\title{
Effects of Total Flavonoids of Rosa Chinensis on Focal Cerebral Ischemia Reperfusion Model in Mice
}

\author{
Xiaoli YAN \\ Institute of Pharmacology in college of pharmacy \\ Henan University of traditional Chinese Medicine \\ Zhengzhou, China \\ e-mail:18768851473@163.com
}

Xiaoyan FANG

Institute of Pharmacology in college of pharmacy Henan University of traditional Chinese Medicine Zhengzhou, China e-mail:guolin555guolin@163.com

\author{
Huisu WU \\ Institute of Pharmacology in college of pharmacy \\ Henan University of traditional Chinese Medicine \\ Zhengzhou, China \\ e-mail:984860564@qq.com \\ Minsan MIAO* \\ Institute of Pharmacology in college of pharmacy \\ Henan University of traditional Chinese Medicine \\ Zhengzhou, China \\ e-mail:miaomingsan@163.com
}

\begin{abstract}
To observe the effects of total flavonoids of Rosa chinensis on focal cerebral ischemia reperfusion model in mice, Method: Nimodipine group, cerebral collaterals group, large, medium and small doses group of the Rosa chinensis total flavonoids were administered with corresponding drugs; Sham operation group, model group were administered the same volume of $0.5 \% \mathrm{CMC}, 1$ times a day, continuous administration of $7 \mathrm{~d}$. After $1 \mathrm{~h}$ at $7 \mathrm{~d}$ to medicine, the focal cerebral ischemia reperfusion model was made by thread embolism method, The blank group only exposed the left blood vessel without Plugging wire, the model mice were only embolism in the left middle cerebral artery to establish an animal model of middle cerebral artery occlusion and reperfusion (MCAO).Result: Compared with the model group, total flavonoids of Rosa chinensis can significantly reduce the loss of neurological function score, animal mortality, serum S-100 beta protein content, reduce the infarct size, the brain tissue has a protective effect. Conclusion: the total flavonoids of Rosa chinensis in each dose group have a better effect on focal cerebral ischemia reperfusion model in mice.
\end{abstract}

Keywords-total flavonoids of rosa chinensis; focal cerebral ischemia reperfusion; animal model

\section{INTRODUCTION}

Cerebral ischemia, also known as stroke, refers to the supply of blood flow of the brain blood vessels to reduce or total occlusion caused by brain tissue degeneration, necrosis caused by a series of symptoms or signs [1], and the clinical manifestations of hemiplegia, slurred speech, reduce tactile and other features. Cerebral ischemia reperfusion injury (CIRI) is refers to the cerebral artery occlusion, cerebral ischemia, hypoxia and lack of energy supply, however restore blood perfusion and oxygen supply, tissue or organ damage aggravate the phenomenon [2].Cerebral ischemia has a high incidence rate in the elderly, with high mortality, high disability rate and high recurrence rate, which brings a great burden to the society and the family [3].

\section{A. Experimental Materials}

1) Experimental drugs, reagents, instrument and animals: Total flavonoids in Rosa chinensis, Laboratory self extraction, the content of total flavonoids was $61.5 \%$, batch number 201208;Nimodipine Tablets, produced by Shandong Xinhua Pharmaceutical Limited by Share Ltd, lot number 1105036;Naoluotong capsules, produced by four Pharmaceutical Group Factory Co. Ltd., No. 201109002.S-100 $\beta$ protein ELISA test kit, produced by R\&D, lot 20121101A.MCAO suture, manufactured by Merck biotech Co. Ltd, No. 2838-100;Enzyme standard instrument, 680 Reader Microplate, Laboratories Bio-Rad; professional image analysis system, AR 4.10.01. NIS-Elements.

Kunming mice, clean grade, male, body weight 15-18g, Wuhan Institute of Biological Products Co., Ltd., the number of mice in this group: 4200499815.

\section{METHODS}

\section{A. Modeling and Administration}

112 mice of KM mice with 26-29g were divided into 7 groups and 16 mice in each group. Nimodipine group (positive control drug, the dosage of $30 \mathrm{mg} / \mathrm{kg}$, pro $0.5 \% \mathrm{CMC}$ with the drug concentration of $3 \mathrm{mg} / \mathrm{ml}$, $0.1 \mathrm{ml} / 10 \mathrm{~g}, 15$ times the clinical dosage); Brain capsule group (positive control drug, the dosage of $750 \mathrm{mg} / \mathrm{kg}$, pro $0.5 \% \mathrm{CMC}$ with the drug concentration of $75 \mathrm{mg} / \mathrm{ml}$, $0.1 \mathrm{ml} / 10 \mathrm{~g}, 15$ times the clinical dosage);Total flavonoids in Rosa chinensis large, medium and small dose group (300mg/kg, $150 \mathrm{mg} / \mathrm{kg}, 75 \mathrm{mg} / \mathrm{kg}$, pro $0.5 \% \mathrm{CMC}$ with $30 \mathrm{mg} / \mathrm{ml}, \quad \quad 15 \mathrm{mg} / \mathrm{ml}, \quad 7.5 \mathrm{mg} / \mathrm{ml}, \quad 0.1 \mathrm{ml} / 10 \mathrm{~g}) ; \quad$ Sham operation group, model group were administered the same volume of $0.5 \% \mathrm{CMC}, 1$ times a day, continuous administration of $7 \mathrm{~d}$.After $1 \mathrm{~h}$ at $7 \mathrm{~d}$ to medicine, left 
incision in the middle of the neck of mice after anesthesia , layer by layer to Isolate and expose the left common carotid artery (CCA) and external carotid artery (ECA), internal carotid artery (ICA). Ligate the common carotid artery and the external carotid artery .Then temporarily clip internal carotid artery with arterial clamp. Besides, cut an incision of $0.2 \mathrm{~mm}$ from $1 \mathrm{~cm}$ of the bifurcation of the common carotid artery. Insert a thread Line bolt with more than $8-10 \mathrm{~mm}$ from bifurcation of common carotid artery into the internal carotid artery until there is resistance. Then blocked the entrance of the middle cerebral artery and ligate internal carotid artery (The blank group only exposed the left blood vessel without Plugging wire); finally gently pulled out the plug line after $2 \mathrm{~h}$. The model mice were only embolism in the left middle cerebral artery to establish an animal model of middle cerebral artery occlusion and reperfusion (MCAO).

\section{B. Detection Index}

Neurological scores after $2 \mathrm{~h}$ : Longa criteria were used to score and Scoring criteria: 0: no neurological deficit symptoms, normal activities. 1 points can't fully extend to the contralateral forepaw; 2: crawling to hemiplegia contralateral circling; 3: when walking, body to hemiplegia side dumping them; 4: unable to walk spontaneously, consciousness loss; 5 points: death. Score 1-3 points for successful modeling, weed out unqualified rats. 0 points and 4 points removed); eyeball blood, half an hour later, centrifugal, supernatant were measured by S-100 $\beta$ protein content; mice were decapitated after rapid stripping brain tissue, placed in -20 degrees Celsius freezer and frozen $15 \mathrm{~min}$, removed the cerebellum, the rest of the olfactory bulb and the lower part of the brain stem, coronal cut four knife, cut into five pieces. Then quickly placed slices in $1 \%$ TTC liquo configured by $\mathrm{pH}=7.2$ phosphate buffer, in 37 DEG C water bath, to avoid light conditions after incubation of $10 \mathrm{~min}$.After taking out in $10 \%$ formalin in the save 24h.After staining, the non ischemic area was rose red, and the infarct area was white. After taking pictures of digital cameras, the total area of the 10 slices of five slices and the area of the infarct area were calculated by image analysis software, and the percentage of the total area of the infarct area was obtained.

\section{RESULTS}

A. The Effect of The Neurological Deficits Score and Mortality on Focal Cerebral Ischemia Model in Mice Was Shown in Table I
TABLE I. THE EFFECT OF NEUROLOGICAL FUNCTION SCORE AND MORTALITY RATE ON FOCAL CEREBRAL ISCHEMIA MODEL IN $\operatorname{MiCE}(\overline{\mathrm{X}} \pm \mathrm{S})$

\begin{tabular}{|c|c|c|c|c|}
\hline group & $\begin{array}{l}\text { Animals( } \\
\mathrm{n})\end{array}$ & $\begin{array}{c}\text { Dose } \\
(\mathrm{mg} / \mathrm{kg})\end{array}$ & $\begin{array}{l}\text { Neurological } \\
\text { function score }\end{array}$ & $\begin{array}{c}\text { Mortality } \\
\text { rate (\%) }\end{array}$ \\
\hline $\begin{array}{c}\text { Sham operation } \\
\text { group }\end{array}$ & 16 & & $0.0 \pm 0.0 * *$ & 0 \\
\hline Model group & 9 & & $3.4 \pm 0.5$ & 43.7 \\
\hline $\begin{array}{l}\text { Nimodipine } \\
\text { group }\end{array}$ & 10 & 30 & $2.6 \pm 0.7^{*}$ & 37.5 \\
\hline $\begin{array}{l}\text { Cerebral } \\
\text { collaterals } \\
\text { group }\end{array}$ & 11 & 750 & $2.4 \pm 0.7 * *$ & 31.2 \\
\hline $\begin{array}{l}\text { HD Rosa } \\
\text { chinensis total } \\
\text { flavonoids } \\
\text { group }\end{array}$ & 12 & 300 & $1.6 \pm 0.7 * *$ & 25.0 \\
\hline $\begin{array}{l}\text { MD Rosa } \\
\text { chinensis total } \\
\text { flavonoids } \\
\text { group }\end{array}$ & 11 & 150 & $1.9 \pm 0.7^{* *}$ & 31.2 \\
\hline $\begin{array}{l}\text { LD Rosa } \\
\text { chinensis total } \\
\text { flavonoids } \\
\text { group }\end{array}$ & 11 & 75 & $2.3 \pm 0.6 * *$ & 31.2 \\
\hline
\end{tabular}

From the table can be seen, The sham operation group had no neurological deficits, There were various degrees of neurological dysfunction in the remaining groups after ischemia $2 \mathrm{~h}$;Compared with the sham operation group, the model group had significant statistical significance $(\mathrm{P}<0.01)$;It shows that the model is successful. Nimodipine group was significantly different $(\mathrm{P}<0.05)$, Which significantly improves neurological impairment; Large, medium and small doses of the Rosa chinensis total flavonoids and cerebral collaterals group have significant statistical significance, which Significantly improve the mice's nerve function injury and reduce the score of neurological deficits.

\section{B. The Effect of Serum S-100 $\beta$ protein and Cerebral Infarction Rate on Focal Cerebral Ischemia Model in Mice Was Shown in Table II, Fig. 1.}

From the table can be seen, compared with the sham operation group, the content of $\mathrm{S}-100 \beta$ protein in the serum of model group was significantly increased $(P<0.01)$ and the area of cerebral infarction was significantly increased $(P<0.01)$, which showed that focal cerebral ischemia reperfusion model was successful. Compared with model group, Large, medium and small doses of the Rosa chinensis total flavonoids, Nimodipine group and cerebral collaterals group can significantly reduce the content of S-100 $\beta$ protein $(P<0.01)$ and Significantly reduced infarct size in the mouse brain $(\mathrm{p}<0.01)$. 


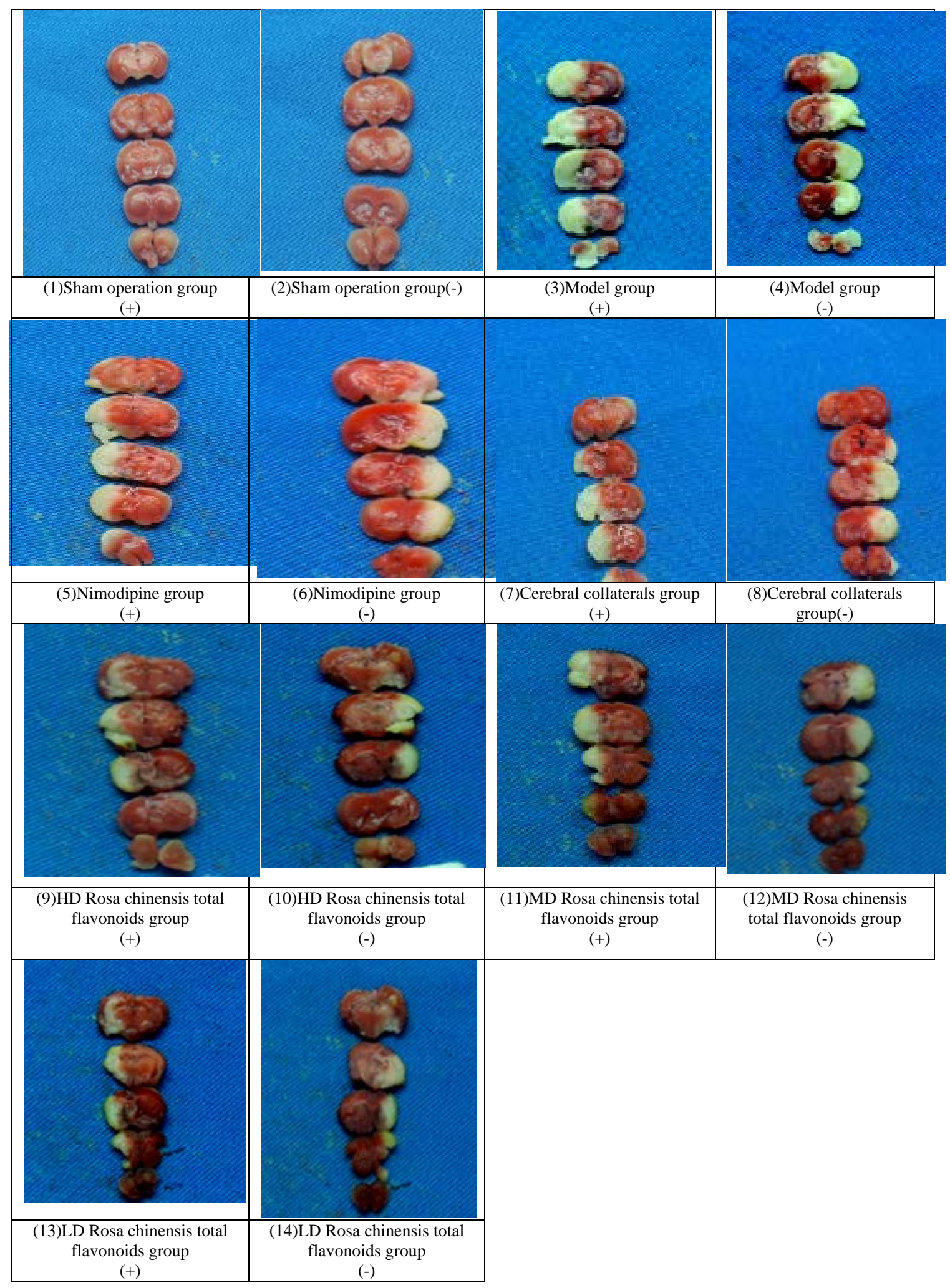

(+): The upward side (-): Opposite side 
TABLE II. THE EFFECT OF SERUM S-100B PROTEIN AND CEREBRAL INFARCTION RATE ON FOCAL CEREBRAL ISCHEMIA MODEL IN

$$
\operatorname{Mice}(\overline{\mathrm{X}} \pm \mathrm{S})
$$

\begin{tabular}{ccccc}
\hline group & $\begin{array}{c}\text { Animals } \\
(\mathrm{n})\end{array}$ & $\begin{array}{c}\text { Dose } \\
(\mathrm{mg} / \mathrm{kg})\end{array}$ & $\mathrm{S}-100(\mathrm{ng} / \mathrm{ml})$ & $\begin{array}{c}\text { Cerebral } \\
\text { infarction rate } \\
(\%)\end{array}$ \\
\hline $\begin{array}{c}\text { Sham } \\
\text { operation } \\
\text { group }\end{array}$ & 16 & & $9.60 \pm 0.47^{* *}$ & $0.00 \pm 0.00^{* *}$ \\
$\begin{array}{c}\text { Model group } \\
\text { Nimodipine } \\
\text { group }\end{array}$ & 10 & 30 & $15.31 \pm 0.71^{* *}$ & $18.71 \pm 3.67^{*}$ \\
$\begin{array}{c}\text { Cerebral } \\
\text { collaterals } \\
\text { group }\end{array}$ & 11 & 750 & $14.31 \pm 0.48^{* *}$ & $17.34 \pm 2.91^{*}$ \\
$\begin{array}{c}\text { HD Rosa } \\
\text { chinensis } \\
\text { total }\end{array}$ & 12 & 300 & $11.17 \pm 0.57^{* *}$ & $16.36 \pm 2.05^{*}$ \\
flavonoids \\
group
\end{tabular}

\section{CONCLUSION}

Compared with the model group, total flavonoids of Rosa chinensis can significantly reduce the loss of neurological function score, animal mortality, serum S-100 beta protein content, reduce the infarct size, the brain tissue has a protective effect. The total flavonoids of Rosa chinensis in each dose group have a better effect on focal cerebral ischemia reperfusion model in mice.

Discussion

Stroke is one of the main diseases threatening human health. With the aging of the population in our country, the incidence of stroke is increasing year by year, among which the most common ischemic stroke is the most common [4].Modern medicine thinks the cerebral ischemia reperfusion injury is a very complicated process, there are many pathophysiological mechanisms involved, including inflammation, oxidative stress and excitotoxicity and the blood-brain barrier, the mechanism of mutual cross effects ultimately lead to irreversible brain injury organization [5].
Chinese medicine believes that qi deficiency and blood stasis is one of the main pathogenesis of ischemic stroke[6].Modern studies suggest that after cerebral ischemia the body's blood can't flow smoothly, resulting in thrombosis, causing the expression of inflammatory molecules and inflammatory cells aggregation, making for neurotoxicity and nerve damage. Therefore, promoting blood circulation and removing blood stasis, clearing away heat and toxic materials is an important treatment for cerebral ischemic diseases in Chinese medicine. Rosa chinensis can regulate menstruation by blood circulation, subdhing swelling and detoxicating [7].Research reported Rosa chinensis flavonoids such as quercetin in the prevention and treatment of diabetes, cardiovascular and cerebrovascular diseases have better application [8].

The focal cerebral ischemia reperfusion model was made by thread embolism method at present [9].It can simulate human permanent and transient focal cerebral ischemia in different states; we can accurately control the time of ischemia and reperfusion. Because the amount of estrogen has a protective effect on the brain, we used the male mouse line embolism method to build the focal cerebral ischemia reperfusion model [10].According to the Longa score standard; the experimental animals were selected to determine the success of the model. S-100 $\beta$ protein is a small molecule acidic protein, when brain injury it released into the cerebrospinal fluid, through the damaged blood brain barrier into the human peripheral blood, so that the blood content increased [11].Therefore, the level of S- $100 \beta$ protein in serum after cerebral ischemia / reperfusion can reflect the degree of injury and death of central nervous system, which is used to judge the degree and prognosis of brain injury [12].

It is a new idea to treat focal cerebral ischemia by promoting blood circulation to remove blood stasis and clearing away heat and toxic drugs. The main flavonoids in Rosa chinensis have good effect of antifungal and antiviral [13]. Through the establishment of focal cerebral ischemia reperfusion model in mice, we found that Rosa chinensis total flavonoids could reduce the loss of nerve function score, animal mortality, serum S-100 beta protein content, reduce the infarct size, and have a protective effect on the brain tissue. In this study, we well explained the pharmacological effects of the Rosa chinensis total flavonoids in the treatment of focal cerebral ischemia, which provides experimental basis for broadening the research and development of Rosa chinensis and clinical practice.

\section{REFERENCE}

[1] Nour M, Liebeskind D S. Imaging of cerebral ischemia: from acute stroke to chronic disorders [J]. Neurol Clin, 2014, 32(1): 193-209.

[2] Zhang W, Miao Y,Zhou S,et al.Involvement of glutamate transport-er-1 in neuroprotection against global brain ischemia-reperfusion in-jury induced by postconditioning in rats[J].International Journal of Molecular Sciences, 2010,11( 11) : 4407-4416.

[3] Lu, Xu Yangmei, Ji Hui. Research progress of [J]. Pharmaceutical development compound Chinese medicine prevention and treatment of cerebral ischemia, 2015, 07:514-524. 
[4] Zhang W,Miao Y,Zhou S,et al.Involvement of glutamate transport-er-1 in neuroprotection against global brain ischemia-reperfusion in-jury induced by postconditioning in rats[J]. International Journal ofMolecular Sciences, 2010,11( 11) : 4407-4416.

[5] Sanderson TH, Reynolds CA, Kumar R, Przyklenk K, Hüttemann M. Molecular Mechanisms of Ischemia-Reperfusion Injury in Brain: Pivotal Role of the Mitochondrial Membrane Potential in Reactive Oxygen Species Generation [J]. Mol Neurobiol. 2013; 47(1):9-23.

[6] Dong Hongtan,Li Lingkang, He Lijuan.etc.Research progress of qi deficiency and blood stasis syndrome in ischemic stroke[J]. World Journal of integrated traditional Chinese and Western Medicine, 2016, 01:131-135.

[7] National Pharmacopoeia Committee. People's Republic of China Pharmacopoeia.. Beijing: Chinese medical science and Technology Press, 2010: 70.

[8] Cheng Bolin, Miao Ming three. Modern research on Chinese rose [J]. Chinese Journal of traditional Chinese medicine, 2014, 05 (29):
711-712.

[9] Sun Nianxia, Gao Weijuan, Yi Zhongliang. The modified suture method in SD rats with focal cerebral ischemia reperfusion mode [J]. China tissue engineering research, 2014, 18 (2):225-230.

[10] Rupadevi M, Parasuraman S, Raveendran R. Proto-col for middle cerebral artery occlusion by an intraluminal suturemethod[J].J Pharm Pharmacol,2011, 2(1) : 36-39.

[11] Song Jiannan, Sun Yi, Zhang Xizhe, Ma Shumin, Zhang Mingli, Hu $\mathrm{Gu}$ Yue. Rat cerebral ischemia / reperfusion after serum S100 beta protein on brain injury diagnosis [J]. Practical medical journal, 2016 , 03 (23): 238-240.

[12] Kaca-Orynska M,Tomasiuk R,Friedman A. Neuron-specific enolase and $\mathrm{S} 100 \mathrm{~B}$ protein as predictors of outcome in ischaemic stroke [J] Neurol NeurochirPol, 2010, 44(5): 459-463.

[13] Liu Mouzhi, Song Xia, Jiang Yuanying, Cao Yongbing, Yan Hua. Research progress on chemical constituents and pharmacological effects of Chinese rose [J]. Journal of pharmaceutical practice, 2015, 03 (33): 198-200+249. 